\title{
Role of Polycation and Cross-Linking in Polyelectrolyte Multilayer Membranes
}

\author{
D. M. Reurink, J. D. Willott, H. D. W. Roesink, and W. M. de Vos* \\ Cite This: ACS Appl. Polym. Mater. 2020, 2, 5278-5289 \\ Read Online
}

ABSTRACT: Alternate deposition of oppositely charged polyelectrolytes is an excellent approach to control the chemistry of interfaces. Membrane technology is one field that benefits from the simplicity and tunability of polyelectrolyte multilayers (PEMs). Herein, ultrafiltration support membranes are coated with PEMs to fabricate nanofiltration membranes. Three PEMs, of different polymeric structures, namely, those of poly(4-styrene sulfonate) (PSS)/poly(allylamine hydrochloric acid) (PAH), PSS/poly(ethyleneimine) (PEI, branched), and PSS/poly(4-aminostyrene) (PAS), are prepared and studied from a fundamental perspective in terms of multilayer composition and cross-linking and also from

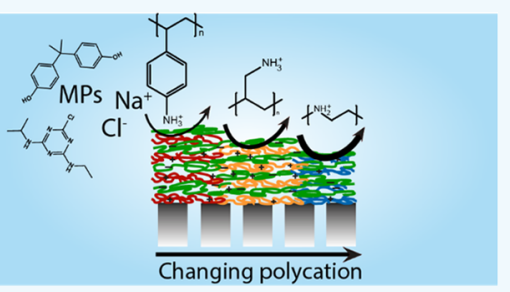
an applied perspective through PEM membrane performance. The low molecular weight cutoff (MWCO) of the PSS/PAH membranes signifies their dense structure (small mesh size), while ion retentions indicate that the dielectric exclusion mechanism is dominant. The PSS/PEI membranes are even denser and have higher selectivities. In contrast, the PSS/PAS membranes are more open, which is likely due to the lower charge density of PAS compared to PEI and PAH. After chemical cross-linking, all of the PEM membranes are denser and therefore more selective and less permeable to water. Micropollutant retention increases for cross-linked PSS/PAH membranes, whereas little to no improvement is seen for cross-linked PSS/PAS and PSS/PEI membranes. Overall, this study shows that completely different membrane properties can be obtained by changing the type of polycation, thus demonstrating the high versatility of PEM-based membranes. In addition, for all PEM membranes, cross-linking acts as an additional tuning parameter that leads to denser and typically more selective layers.

KEYWORDS: polyelectrolyte, multilayer, membranes, cross-linking, micropollutants

\section{INTRODUCTION}

Building polyelectrolyte multilayers (PEMs) is a simple and versatile approach to modify the chemistry of surfaces and thus control various interfacial phenomena. Consequently, over the last two decades, significant interest has been focused on the preparation of PEMs and in understanding their behavior. The list of parameters that can be used to tune PEMs is vast and includes salt concentration, ${ }^{1} \mathrm{pH},{ }^{2,3}$ polyelectrolyte (PE) type, ${ }^{4}$ the number of layers, ${ }^{5}$ cross-linking, ${ }^{6}$ and $\mathrm{PE}$ molecular weight. $^{7}$ In addition, various PEM fabrication methods exist including dip-coating (the most common), spray-coating, spincoating, dynamic-coating, and electrodeposition. ${ }^{8}$ Over the years, PEMs have found interest in fields such as membrane technology, ${ }^{9}$ catalysis, ${ }^{10}$ semiconductors, ${ }^{11}$ drug delivery, ${ }^{12}$ and optical devices ${ }^{13}$ since layer thickness, affinity, and refractive indices can be controlled. Concerning the field of membranes, the layer-by-layer (LbL) dip-coating approach ${ }^{14}$ to preparing PEMs has become widely used to coat a selective layer on the inner surface of hollow fiber support membranes. ${ }^{15}$ In addition, PEs have been used to create microfiltration membranes with antiviral properties, ${ }^{16}$ to modify electrodialysis membranes to increase selectivity, ${ }^{17,18}$ and to prepare nanofiltration (NF) membranes ${ }^{15}$ that are already used for commercial applications. $^{19}$
Many PE combinations have been studied to fabricate PEM membranes. Coating poly(diallyldiammonium chloride) (PDADMAC) and poly(4-styrene sulfonate) (PSS) multilayers on ultrafiltration (UF) support membranes creates successful NF membranes with long-term physical and chemical stability (e.g., toward hypochlorite, a typical membrane-cleaning chemical). ${ }^{20}$ In addition, PEM membranes based on PDADMAC and PSS show high monovalent ion selectivity toward sodium-magnesium, ${ }^{21}$ chloride-sulfate, ${ }^{22}$ fluoride, ${ }^{23,24}$ and phosphate. ${ }^{25}$ Poly(vinylamine) in combination with poly(vinyl sulfonate) was used to obtain PEM membranes with reverse-osmosis properties. ${ }^{26,27}$ Interestingly, for PSS/ PDADMAC PEMs, an excess of PDADMAC within the bulk of the multilayer ${ }^{28}$ is found, and this directly influences membrane performance by making the bulk of the multilayer positively charged. ${ }^{29}$ Another well-studied PE pair is the combination of poly(allylamine hydrochloric acid) (PAH) with PSS. For this PE pair, a recent study reports the long-term

Received: September 7, 2020

Accepted: October 20, 2020

Published: October 29, 2020 
stability of this PEM, even at an extremely low $\mathrm{pH}(\mathrm{pH}$ of 1$) .^{30}$ Furthermore, the polycation, $\mathrm{PAH}$ in this case, is also found to be in excess within the bulk of the multilayer. ${ }^{1,31}$ Charge excesses in the PDADMAC/PSS and PAH/PSS systems are more commonly found and tend to have an excess of the polycation in the bulk of the multilayer. ${ }^{28,31}$ Such a PE excess depends on the given PE pair and can be beneficial to separation performance. However, this PE excess can also lead to swelling of the multilayer, which increases its effective pore size (i.e., makes the layer less dense/more open). It is therefore of interest to study the performance of PEM membranes that exhibit different degrees of excess PE and thus different swelling behaviors.

The primary amine groups along $\mathrm{PAH}$ chains can be crosslinked to increase salt retentions ${ }^{32,33}$ and stability. ${ }^{34}$ Crosslinking of PEMs has been achieved using glutaraldehyde (GA) and using GA in combination with ultraviolet light (UV). ${ }^{32}$ All studies using the PAH/PSS combination observed densification of the multilayers and increases in membrane selectivity toward ions after cross-linking; however, this came at the cost of lower permeability. In this study, PEMs are coated on the inside of hollow fiber support membranes. Coating on the inside prevents techniques like UV light from being used for cross-linking, and for this reason, GA is used for cross-linking.

While there does already exist separate literature on the buildup of different PEMs as well as the performance of different PEM-coated membranes, what is lacking is a comprehensive study that directly links multilayer buildup with PEM membrane performance for a variety of probe molecules. This is what we present in this work. Herein, a critical evaluation of the effect of multilayer composition and cross-linking on membrane performance depending on the type of PEM is presented. The polyanion PSS is combined with three different weakly charged polycations of varying polymeric structures, namely, the linear and aliphatic $\mathrm{PAH}$, the branched poly(ethyleneimine) (PEI), and the aromatic poly(4aminostyrene) (PAS). The three weak polycations used all contain primary amine functional groups and thus can be readily cross-linked with GA. In addition, the PSS/PAH multilayers are built using three different salt concentrations: 5 , 50 , and $500 \mathrm{mM}$. All PEMs are characterized in terms of their fundamental buildup using reflectometry (PE adsorption) and $\zeta$-potential (surface charge) measurements. Subsequently, to obtain a deeper understanding on the relationship between PEM membrane performance and the fundamental PEM buildup, including parameters like bulk and surface charge as well as density, the PEM membranes are evaluated in terms of their ability to retain various ions and organic molecules. Finally, all PEM membranes are studied for the application of micropollutant retention.

\section{MATERIALS AND METHODS}

Materials. Poly(allylamine hydrochloric acid) (PAH, $M_{\mathrm{W}}=$ $150000 \mathrm{~g} \cdot \mathrm{mol}^{-1}, 40 \mathrm{wt} \%$ in water) was purchased from Nittobo Medical, Japan; poly(4-aminostyrene) (PAS, $M_{\mathrm{W}}>150000 \mathrm{~g} \cdot \mathrm{mol}^{-1}$ ) was from Polysciences Europe Gmbh; and branched poly(ethyleneimine) (PEI, primary, secondary, and tertiary amine ratio: 1:1.2:0.76, $M_{\mathrm{W}}=75000 \mathrm{~g} \cdot \mathrm{mol}^{-1}$ ) and poly(sodium 4-styrene sulfonate) (PSS, $M_{\mathrm{W}}=200000 \mathrm{~g} \cdot \mathrm{mol}^{-1}, 30 \mathrm{wt} \%$ in water) were purchased from Sigma-Aldrich. Glutaraldehyde (25 wt \% in water) was purchased from Alfa Aesar. Sodium chloride was obtained from Akzo Nobel, magnesium chloride was from Boom B.V., and magnesium sulfate and sodium sulfate were from Sigma-Aldrich. Sulfamethoxazole was purchased from Fluka, and atenolol, atrazine, bezafibrate, bisphenol A, bromothymol blue, naproxen, and phenolphthalein were obtained from Sigma-Aldrich. All chemicals were used without any further purification.

Tight ultrafiltration hollow fiber membranes are used as supports and were provided by NX Filtration B.V. (Enschede, The Netherlands). The fibers have a positive charge, a standard permeability of $200 \mathrm{~L} \cdot \mathrm{m}^{-2} \cdot \mathrm{h}^{-1} \cdot \mathrm{bar}^{-1}$, a standard molecular weight cutoff of $25 \mathrm{kDa}$ (indicative of the pore size), and an inner diameter of $0.68 \mathrm{~mm}$. The membranes are asymmetrical with the smallest pore size on the inside of the hollow fiber. Silicon wafers were obtained from WaferNet Inc. (San Jose).

Reflectometry. Polyelectrolyte multilayer (PEM) growth was quantitatively measured using optical fixed-angle reflectometry, which allows an in situ and quantitative measurement of the adsorbed amount of polyelectrolytes on top of a silicon wafer. Polyelectrolyte solutions are alternately applied in a flow cell containing a silicon wafer with an optical spacer of $82 \mathrm{~nm}$-thick silicon oxide layer. ${ }^{35}$ Adsorption is measured at the stagnation point where the hydrodynamics at this point are well-defined and the mass transfer is diffusion-limited. From the adsorbed amounts as obtained from reflectometry, a dry layer thickness can be estimated on the basis of the PEM density. ${ }^{35}$ PEMs are prepared by first flowing through a solution containing PAH, PEI, or PAS (the polycation) with the desired salt concentration until a stable adsorption plateau is reached. The time to reach stable adsorption is not stable, but it was in all cases at least $2 \mathrm{~min}$ and at maximum $10 \mathrm{~min}$. Subsequently, the wafer is rinsed with a solution of the same ionic strength but without any polyelectrolyte. After rinsing, a solution containing PSS (polyanion) with the same salt concentration is passed through the cell. After the polyanion coating step, the wafer is rinsed in the same manner as after the polycation coating step. This cycle finishes one bilayer and is repeated until 11 bilayers ( 22 layers) are constructed on the silicon wafer. All polyelectrolyte solutions contain $0.1 \mathrm{~g} \cdot \mathrm{L}^{-1}$ of the given polyelectrolyte. For the PSS/PAH multilayers, salt concentrations of 5,50 , and $500 \mathrm{mM} \mathrm{NaCl}$ were used. For the PSS/PEI and PSS/PAS multilayers, $50 \mathrm{mM} \mathrm{NaCl}$ was used. The salt concentration of all polyelectrolyte and rinsing solutions was kept the same during multilayer growth/buildup. The polycation solutions were adjusted to have a $\mathrm{pH}$ of 2 , while the $\mathrm{pH}$ values of the PSS and rinsing solutions were 5.5 and 5.5 , respectively.

Optical fixed-angle reflectometry uses monochromatic light of a $\mathrm{He}-\mathrm{Ne}$ laser $(632.8 \mathrm{~nm})$ that is linearly polarized and reflected from the silicon wafer at the Brewster angle $\left(71^{\circ}\right)$. The polarized light is subsequently split into its parallel and perpendicular components, and both component intensities are measured in the detector. The signal $(S)$ is defined as the fraction of the parallel over the perpendicular components. The difference between the signal $(\Delta S)$ and the signal at the initial state $\left(S_{0}\right)$ over the initial state signal is proportional to the adsorbed amount on the silicon wafer, as shown in eq 1 .

$$
\Gamma_{\mathrm{i}}=Q_{\mathrm{i}} \cdot \frac{\Delta S}{S_{0}}
$$

In eq $1, \Gamma$ is the adsorbed mass $\left(\mathrm{mg} \cdot \mathrm{m}^{-2}\right)$ and $Q$ is the sensitivity factor $\left(\mathrm{mg} \cdot \mathrm{m}^{-2}\right)$. The sensitivity factor or the $Q$-factor depends on the refractive indices $(n)$ of the used materials, thicknesses $(d)$ of the PEM and silicon oxide layer, angle of incidence of the laser light, and the refractive index increment $(\mathrm{d} n / \mathrm{d} c)$ for the PEs. The refractive index increments $(\mathrm{d} n / \mathrm{d} c)$ were determined using a Schmidt + Haensch ATR-lambda refractometer at wavelengths of 590 and 700 $\mathrm{nm}$ at five different PE concentrations (see Figure S1). For each PE, the background salt and $\mathrm{pH}$ were the same as the coating solutions; $\mathrm{PAH}(\mathrm{pH}=2$ and 5,50 , or $500 \mathrm{mM} \mathrm{NaCl})$, PEI $(\mathrm{pH}=2$ and $50 \mathrm{mM}$ $\mathrm{NaCl}), \mathrm{PAS}(\mathrm{pH}=2$ and $50 \mathrm{mM} \mathrm{NaCl})$, and $\mathrm{PSS}(\mathrm{pH}=5.5$ and 5 , 50 , or $500 \mathrm{mM} \mathrm{NaCl})$. The refractive index increments and the various sensitivity/ $Q$-factors (by an optical model using a silicon wafer with an $82 \mathrm{~nm}$ silicon oxide layer) are given in Table 1 for each polyelectrolyte.

The excess amount of monomers $\left(\sum_{\text {monomer }}, \mathrm{mmol} \cdot \mathrm{m}^{-2}\right)^{1}$ is defined as the total monomeric amount of adsorbed polycation $\left(\Gamma_{\mathrm{PC}}\right)$ 
Table 1. Refractive Index Increment Values and the Accompanying Q-Factor Used for Calculating the Adsorption of Polyelectrolytes in This Study by Means of Reflectometry

\begin{tabular}{ccc} 
polyelectrolyte & $\begin{array}{c}\text { refractive index increment } \\
\mathrm{d} n / \mathrm{d} c\left(\mathrm{~mL} \cdot \mathrm{g}^{-1}\right)\end{array}$ & $\begin{array}{c}\text { sensitivity }(Q) \text { factor } \\
\left(\mathrm{mg} \cdot \mathrm{m}^{-2}\right)\end{array}$ \\
PSS (-) & 0.252 & 18.9 \\
PAH (+) & 0.227 & 20.9 \\
PEI (+) & 0.319 & 14.9 \\
PAS (+) & 0.295 & 16.1 \\
\hline
\end{tabular}

minus the total monomeric amount of adsorbed PSS ( $\left.\Gamma_{\text {PSS }}\right)$ at a given layer number of polycation $(i)$ and polyanion $(j)$ according to eq 2

$$
\sum \text { monomer }=\sum_{i} \Gamma_{\mathrm{PC}}-\sum_{j} \Gamma_{\mathrm{PSS}}
$$

Here, the assumption is that there is no removal of any of the previously adsorbed polyelectrolytes. To obtain an excess monomer ratio, eq 3 is used

$$
\text { excess monomer ratio }=\frac{\sum_{i} \Gamma_{\mathrm{PC}}-\sum_{j} \Gamma_{\mathrm{PSS}}}{\Gamma_{\text {total }}}
$$

where the excess monomer (from eq 2) is divided by the total monomeric adsorption $\left(\Gamma_{\text {total }}\right)$ at a given layer number $(i+j)$.

Polyelectrolyte Multilayer Fabrication. Tight hollow fiber ultrafiltration membranes were coated in a bundle containing 20 fibers using a dip-coat robot made from LEGO Mindstorms in cylinders containing the desired solutions. The positively charged support membranes were first immersed in a solution containing $0.1 \mathrm{~g} \cdot \mathrm{L}^{-1}$ polyanion and the appropriate ionic strength for $15 \mathrm{~min}$. Subsequently, the membranes were rinsed in three separate cylinders containing the same ionic strength as the coating solutions for $5 \mathrm{~min}$ per rinsing step. Finally, the membranes were immersed in a solution containing $0.1 \mathrm{~g} \cdot \mathrm{L}^{-1}$ polycation and the desired ionic strength. This cycle completes one bilayer and is repeated until ten bilayers are coated; each PEM is terminated by the polycation. Equal concentrations are used because the formation of PEMs is known to be hardly influenced by the polyelectrolyte concentration. ${ }^{36}$ Furthermore, 10 bilayers were chosen to ensure that in all cases the prepared membrane where in the layer-dominated regime, where the applied PEM is fully responsible for the observed separation behavior.

Three different salt concentrations of 5,50 , and $500 \mathrm{mM} \mathrm{NaCl}$ were used to fabricate three different $[\mathrm{PSS} / \mathrm{PAH}]_{10}$ PEMs (the notation used here corresponds to a final PEM made up of 10 bilayers of PSS and PAH). For fabrication of the $[\mathrm{PSS} / \mathrm{PEI}]_{10}$ and $[\mathrm{PSS} /$ PAS $]_{10}$ PEMs, a salt concentration of $50 \mathrm{mM} \mathrm{NaCl}$ was used. The $\mathrm{pH}$ values for the polyanion (PSS) and the polycation (PAH, PEI, and PAS) solutions were 5.5 and 2, respectively. The $\mathrm{pH}$ of the rinsing solutions was adjusted to 5.5 .

Cross-linking was performed in an aqueous solution of demineralized water containing $0.1 \mathrm{wt} \%$ glutaraldehyde at a $\mathrm{pH}$ of 5.5 in a volumetric cylinder. Cross-linking a primary amine with GA is called a Schiff-base reaction, during which an imine bond is formed. ${ }^{6}$ After preparing the hollow fiber PEM membranes, they were immersed in the cross-linking solution in the same manner as the dip-coating steps for $16 \mathrm{~h}$. After cross-linking, the PEM membranes were rinsed in demineralized water for at least $2 \mathrm{~h}$. Before drying, the membranes were immersed for at least $4 \mathrm{~h}$ in an aqueous solution containing 15 wt \% glycerol to prevent pore collapse of the UF support membranes. After being dried, the hollow fibers were potted into modules with an approximate active fiber length of around $17 \mathrm{~cm}$. For each PEM membrane, five separate single fiber modules were prepared and studied.

$\zeta$-Potential. For the $\zeta$-potential measurements, prepared PEM hollow fiber membranes were fixed with glue in polyethylene tubes in such a way that the membranes were unable to permeate from the lumen to the shell side (inside to out) but there can remain crossflow through the lumen side (inside) of the hollow fiber membrane. For the measurements, three different modules were fabricated and measured. $\zeta$-Potential was measured by an electrokinetic analyzer (SurPass, Anton Paar, Graz Austria) by flowing a $5 \mathrm{mM} \mathrm{KCl}$ solution under a given pressure difference through the hollow fiber module. The flow through the module at a defined pressure difference $(\mathrm{d} p, \mathrm{~Pa})$ creates a streaming current $(\mathrm{d} I, \mathrm{~A})$ from which the $\zeta$-potential $(\zeta, \mathrm{V})$ can be calculated using eq 4

$$
\zeta=\frac{\mathrm{d} I}{\mathrm{~d} p} \cdot \frac{\eta}{\varepsilon \cdot \varepsilon_{0}} \cdot \kappa_{\mathrm{B}} \cdot R
$$

where $\eta$ is the solution viscosity in $\mathrm{Pa} \cdot \mathrm{s}, \varepsilon$ is the dielectric constant of the electrolyte $(-), \varepsilon_{0}$ is the dielectric constant of vacuum $(-)$, the specific conductivity of the solution is defined as $\kappa_{\mathrm{B}}\left(\mathrm{S} \cdot \mathrm{m}^{-1}\right)$, and $R$ $(\Omega)$ is the measured Ohmic resistance of the hollow fiber module.

Membrane Performance Measurements. The performance of the PEM hollow fiber membranes was determined by measuring permeability, salt retention, molecular weight cutoff, and micropollutant retention. All measurements applying a hydraulic pressure were performed on a crossflow setup. This setup has a rotary vane pump (BN71B4 pump motor, Bonfiglioli, Italy; IMTI $1.5 \mathrm{M}$ inverter, Electroil, Italy; PA411 pump head, Fluid-o-Tech, Italy).

Permeability. Membrane permeability toward water was measured with Milli-Q (18.2 M 2 ) water at an applied transmembrane pressure of 6.2 bars using the setup described above. The time was measured using a stopwatch, and at least $10 \mathrm{~mL}$ was collected before measuring the permeate weight. Using the time, permeate weight, and the applied transmembrane pressure, the permeability can be calculated as in eq 5

$$
\text { permeability }=\frac{m_{\mathrm{p}}}{\rho_{\mathrm{w}} \cdot A_{\mathrm{i}} \cdot t \cdot P_{\mathrm{tmp}}}
$$

where $m_{\mathrm{p}}$ is the mass of the collected permeate in $\mathrm{g}, \rho_{\mathrm{w}}$ is the density of water in $\mathrm{g} \cdot \mathrm{L}^{-1}, A_{\mathrm{i}}$ is the inner membrane surface area in $\mathrm{m}^{-2}, t$ is the time in hours, and $P_{\text {tmp }}$ is the transmembrane pressure in bar.

Salt Retention. Retentions of $\mathrm{NaCl}, \mathrm{Na}_{2} \mathrm{SO}_{4}, \mathrm{MgCl}_{2}$, and $\mathrm{MgSO}_{4}$ were determined separately at a concentration of $5 \mathrm{mM}$ in demineralized water. These measurements were performed on the same setup as described above, under a crossflow condition at an applied pressure of 6.2 bars and at a crossflow velocity of $1 \mathrm{~m} \cdot \mathrm{s}^{-1}$. This crossflow velocity corresponds to a Reynolds number of 675 , well within the laminar flow regime. The retention $R$ was determined by measuring the conductivity of both the permeate and feed using the relationship presented in eq 6

$$
R=\frac{\Delta C}{C_{\text {feed }}} \times 100 \%
$$

where $\Delta C$ and $C_{\text {feed }}$ correspond to the difference between the feed and permeate concentration and the feed concentration, respectively.

Molecular Weight Cutoff. Using a feed mixture of ethylene glycol (EG), diethylene glycol (DEG), and several molecular weights of poly(ethylene glycol) (PEG) molecules-EG62, DEG106, PEG200, PEG400, PEG600, PEG1000, PEG1500, and PEG2000at a concentration of $1 \mathrm{~g} \cdot \mathrm{L}^{-1}$ each, the molecular weight cutoff of the membranes was determined. The measurement was performed in crossflow and operated at 2 bar and a crossflow velocity of $1 \mathrm{~m} \cdot \mathrm{s}^{-1}$ per module containing one hollow fiber. Both permeate and feed samples were taken and analyzed via gel permeation chromatography with a size exclusion column (SEC) (Agilent 1200/1260 Infinity GPC/SEC series, Polymer Standards Service data center and column compartment). Solutions were flown over two Polymer Standards Service Suprema $8 \times 300 \mathrm{~mm}^{2}$ columns in series: $1000 \AA, 10 \mu \mathrm{m}$ followed by $30 \AA, 10 \mu \mathrm{m}$ at $1 \mathrm{~mL} \cdot \mathrm{min}^{-1}$, and concentrations were measured via refractive index measurements. In this study, a PEM has defects or pinholes when the sieving curve never reaches zero for the used mixture of PEG molecules.

Micropollutant Retention. The retention of micropollutants was measured using a cocktail containing atenolol, atrazine, bezafibrate, bisphenol A, bromothymol blue, naproxen, phenolphthalein, and 
sulfamethoxazole. Of each micropollutant, $3 \mathrm{mg} \cdot \mathrm{L}^{-1}$ was dissolved and the $\mathrm{pH}$ of the solution was adjusted to 5.8. Using a crossflow setup, retention was measured at a pressure of $6.2 \mathrm{bar}$ and $1 \mathrm{~m} \cdot \mathrm{s}^{-1}$ crossflow velocity per module. Prior to measuring permeate samples, the filtration was allowed to stabilize for at least $16 \mathrm{~h}$ to remove the influence of adsorption on the reported retention values. ${ }^{37} \mathrm{~A}$ calibration range was prepared from the feed, and from each module around $2 \mathrm{~mL}$ of permeate was collected. Analysis of all samples was performed by high-pressure liquid chromatography (HPLC, Dionex Ultimate 3000 , Eluent: water, acetonitrile, and $0.1 \%$ phosphoric acid) over a Thermo Scientific Acclaim RSLC 120 C18 column $(2.2 \mu \mathrm{m}$, $2.1 \times 100 \mathrm{~mm}^{2}$ ). Here, the column oven temperature was $40^{\circ} \mathrm{C}$ and the flow rate of the mobile phase was $0.8 \mathrm{~mL} \cdot \mathrm{min}^{-1}$. The used eluent starts with $5 \%$ water and linearly increases until it contains $90 \%$ water, acetonitrile, and $0.1 \%$ phosphoric acid. The micropollutant concentrations were determined via UV-vis detection at $225 \mathrm{~nm}$ and bromothymol blue at $430 \mathrm{~nm}$. Subsequently, micropollutant retention was calculated using eq 6 .

\section{RESULTS AND DISCUSSION}

In this section, the results will be presented and discussed in two distinct parts. First, the fundamental buildup of the polyelectrolyte multilayers (PEMs) and the $\zeta$-potential of the final multilayers will be discussed. Next, the PEM-coated hollow fiber membranes and their nanofiltration properties are studied in three subsections: the effect of multilayer composition on membrane performance, the effect of crosslinking on membrane performance, and the application of the PEM membranes for micropollutant removal.

Multilayer Characterization. Optical fixed-angle reflectometry is a tool to quantitatively study the buildup of PEMs. ${ }^{15}$ In this study, the effect of polycation type on the preparation of PSS-based multilayers is studied. The three polycations used are $\mathrm{PAH}$, branched PEI, and PAS (chemical structures and monomer molecular weights are shown in Figure 1). From

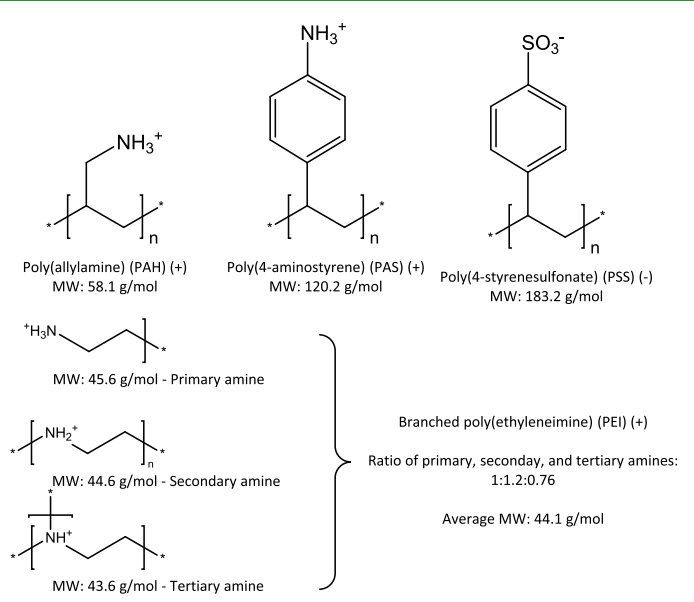

Figure 1. Chemical structures, full names, abbreviation, charge, and molecular weight of the polyelectrolyte monomers used. Monomers are shown in their charged form.

these PEMs, PSS/PAH is well known-using branched PEI for PEM membranes has been performed on pressure-driven ${ }^{38}$ and ion-exchange membranes ${ }^{39}$ - whereas PAS is a polycation that is known to build multilayers ${ }^{40}$ but new to the PEM membrane literature. The PSS/PAH multilayers were prepared at three different $\mathrm{NaCl}$ concentrations of 5, 50, and $500 \mathrm{mM}$, whereas the buildup of the PSS/PEI and PSS/PAS multilayers is studied at $50 \mathrm{mM} \mathrm{NaCl}$. All polycation solutions were adjusted to $\mathrm{pH}$ of 2 since it is shown that high selectivities are obtained. ${ }^{41}$ Furthermore, the polycation chains are stretched at a low $\mathrm{pH}$, creating the possibility to form dense layers. ${ }^{42}$ First focusing on the PSS/PAH systems shown in Figure 2A, it is
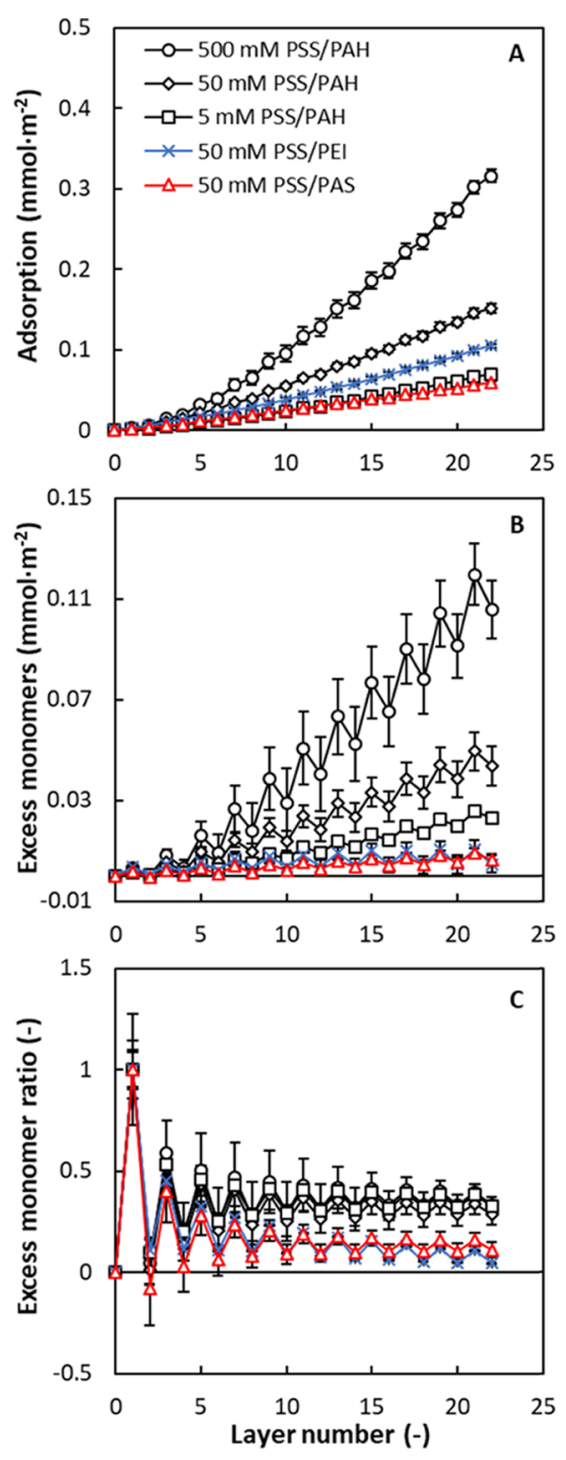

Figure 2. (A) Molar adsorption as a function of layer number for PSS/PAH PEMs (5, 50, and $500 \mathrm{mM})$, PSS/PEI PEM (50 mM), and PSS/PAS PEM (50 mM). (B) Excess monomer determined by calculating the amount of excess monomers accumulating per adsorption step. (C) Excess monomers of the PEMs divided by the total molar adsorption. For both (B) and (C), a positive value corresponds to an excess amount of polycations within the multilayer. Error bars are standard errors of measurement on three separate samples.

seen that the adsorbed molar amount of the polyelectrolytes increases when higher salt concentrations are used, which is in line with typical PEM behavior at higher ionic strengths. ${ }^{15}$ At low salt concentrations, the entropic gain from counterion release is large, leading to the charge of the polyelectrolytes within the multilayer being mainly intrinsically compensated by the opposite polyelectrolyte. ${ }^{43}$ When the salt concentration increases, the entropic gain of the counterion release decreases, increasing the degree of extrinsic charge compensation. ${ }^{36,43,44}$ The intrinsic and extrinsic charge compensation is seen back in the reflectometry results, where at $5 \mathrm{mM}$, the buildup of the 
PSS/PAH multilayer is linear. For 50 and $500 \mathrm{mM}$, initially, in the first few layers, the PSS/PAH systems grow nonlinearly. After these initial layers, the buildup is linear and larger at higher salt concentrations, similar to what has been reported in other studies due to the more extrinsic charge compensation. ${ }^{1}$ When the polycation is changed to PEI, it is observed that the molar adsorption is lower than that of PSS/PAH multilayers built at the same salt concentration. With PAS as a polycation, the adsorption is even lower and closer to the PSS/PAH multilayer constructed at $5 \mathrm{mM} \mathrm{NaCl}$. The adsorption of both PEI and PAS is lower and is most likely due to the differences in the polyelectrolyte structure compared to PAH. Here, PEI has a branched structure and PAS has a bulky aromatic structure and possible aromatic ring stacking, meaning that both of these polycations will have a decreased mobility and therefore can penetrate less into the multilayer, resulting in a lower adsorption for PEI and PAS.

In Figure $2 \mathrm{~B}$, the amount of excess monomer in the multilayer as a function of the number of layers is given (according to eq 2). Here, a positive value corresponds to an excess of polycation within the multilayer. In Figure $2 \mathrm{~B}$, it is observed that for the PSS-/PAH-based multilayers, the amount of excess polycation increases when higher salt concentrations are used during multilayer preparation. This is simply because of the increased adsorption at higher salt concentrations. An improved measure is therefore the excess monomer ratio (Figure 2C), which gives the monomer excess normalized by the layer adsorbed amount as calculated by eq 3. This normalized monomer excess is constant for all three ionic strengths, meaning that the excess amount of $\mathrm{PAH}$ with respect to PSS is independent of the salt concentration used during layer preparation.

For the PSS/PEI and PSS/PAS multilayers built at $50 \mathrm{mM}$ $\mathrm{NaCl}$, a different trend is seen where now the amount of excess polycation accumulating within the multilayer is significantly lower than the PSS/PAH multilayers. When looking at the excess monomer ratio of Figure 2C, it is observed that for the PSS/PAH multilayers, the monomer excess levels off at around $30-40 \%$ of excess PAH (with respect to PSS), in line with other studies. ${ }^{1,31}$ For the PSS/PEI multilayers, in the first few layers, PEI is $10-40 \%$ in excess with respect to PSS; this gradually decreases to $5-11 \%$ as the number of layers increases. The PSS/PAS multilayer is similar to the PSS/PEI multilayers, with the amount of excess polycation with respect to PSS stabilizing at higher layer numbers, at a charge ratio for PAS of $10-16 \%$. Again, this lower polycation excess for the PEI and PAS multilayers compared to the PAH multilayer can be related to the differences in the polycation steric bulk: branched and aromatic side groups vs linear and small side groups. It is important to note that the three polycations used are all weakly charged. Their ionizable nature means that they do not need to be completely charged during multilayer formation (i.e., during adsorption), and this can lead to polycation excesses since the strong polyanion PSS is always fully charged. In the literature, it is common for PSS/PAH ${ }^{1,31}$ multilayers to have an excess of PAH, whereas for PSS/PEI and PSS/PAS multilayers, there is no literature on monomer/ charge excess to the best of our knowledge. For PSS/PAH multilayers, the excess of $\mathrm{PAH}$ is attributed to the high charge density of PAH, as the PAH monomer is quite small. In this case, the Bjerrum length is larger than the average distance of the PAH charges, and as a consequence, Manning condensation occurs, which immobilizes counterions on the charges of PAH and therefore an excess of PAH can accumulate within the layer. ${ }^{1}$ This excess amount of polycation can lead to more extrinsic charge compensation and thus more swelling than for an intrinsically charge-compensated multilayer. ${ }^{45}$ The results presented in Figure 2 show that an excess amount of polycation is also present in PSS/PEI and PSS/PAS multilayers. However, this excess is much lower than in PSS/ PAH multilayers and could be due to a better match between the polycation and polyanion since PAS and PSS have similar chemical structures and the branched structure of PEI makes it more flexible to compensate charges.

Table 2 presents the measured $\zeta$-potential of the uncoated and PEM-coated hollow fiber membranes; the PEMs have 10

Table 2. $\zeta$-Potential of the Support Membrane and the PEM Membranes Non-Cross-Linked and Cross-Linked ${ }^{a}$

$\begin{array}{lcc} & \begin{array}{c}\zeta \text {-potential }(\mathrm{mV}) \text { non- } \\ \text { cross-linked }\end{array} & \begin{array}{c}\zeta \text {-potential }(\mathrm{mV}) \\ \text { cross-linked }\end{array} \\ \text { support membrane } & 29 \pm 9 & \mathrm{NA} \\ 5 \mathrm{mM}-[\mathrm{PSS} / \mathrm{PAH}]_{10} & 11 \pm 2 & 1 \pm 2 \\ 50 \mathrm{mM}-[\mathrm{PSS} / \mathrm{PAH}]_{10} & 18 \pm 6 & 10 \pm 2 \\ 500 \mathrm{mM}-[\mathrm{PSS} / \mathrm{PAH}]_{10} & 16 \pm 3 & 17 \pm 2 \\ 50 \mathrm{mM}-[\mathrm{PSS} / \mathrm{PEI}]_{10} & -26 \pm 9 & -27 \pm 2 \\ 50 \mathrm{mM}-[\mathrm{PSS} / \mathrm{PAS}]_{10} & -14 \pm 4 & -13 \pm 1\end{array}$

${ }^{a}$ Error bars are standard deviations of measurements on three different membrane modules.

bilayers, and all PEMs are terminated with the polycation. The $\zeta$-potential measurements reveal the charge of the final surface and show that the uncoated support membrane has a positive surface charge. All of the $[\mathrm{PSS} / \mathrm{PAH}]_{10}$ multilayer membranes have a positive surface charge, while both the $[\mathrm{PSS} / \mathrm{PEI}]_{10}$ and $[\mathrm{PSS} / \mathrm{PAS}]_{10}$ multilayers have a negative surface charge, even though the polycation is the terminating layer. The measured negative surface charge for the PEI and PAS membranes is somewhat surprising; however, the polycations are weak PEs and as discussed above they do not need be fully charged during buildup or within the resultant multilayer, whereas PSS is a strong PE and is therefore always fully charged. This means that although an excess of polycation is measured within the multilayers (Figure 2C), it is still possible for them to have a negatively charged surface. Moreover, the excess of PEI and PAS (5-16\%) is much lower than that of PAH (30-40\%). Cross-linking shows little to no influence on the measured $\zeta$ potential, and overall, it can be concluded that cross-linking does not significantly influence the surface charge of the PEMs.

In summary for this section, the adsorption behavior and $\zeta$ potential of PSS/PAH, PSS/PEI, and PSS/PAS multilayers were studied. For all of the PSS/PAH multilayers, an excess monomer ratio of PAH of $30-40 \%$, whereas for the PSS/PEI and the PSS/PAS multilayers a much lower excess monomer ratio of polycation was found: 5-11 and $10-16 \%$, respectively. The $\zeta$-potential of the multilayers showed that the PSS/PAH membranes have a positive surface charge; however, the PSS/ PEI and PSS/PAS multilayers have a negative surface charge even though the multilayers are terminated by the polycation. In the next section, membrane performance is measured using ions and various organic molecules, and from this, more information about the bulk-layer properties of the PEMs as well as the effect of cross-linking will be attained.

Nanofiltration Results. In this section, the nanofiltration performances of the different PEM systems are presented and 
discussed. As before, five different PEM membranes have been studied: $[\mathrm{PSS} / \mathrm{PAH}]_{10}$ multilayers prepared at 5,50 , and 500 $\mathrm{mM} \mathrm{NaCl}$, as well as a $[\mathrm{PSS} / \mathrm{PEI}]_{10}$ and a $[\mathrm{PSS} / \mathrm{PAS}]_{10}$ multilayer both prepared at $50 \mathrm{mM} \mathrm{NaCl}$. The section is split up into three parts: the effect of polycation and multilayer composition on membrane performance; the effect of crosslinking on multilayer composition and membrane performance; and the application of the fabricated PEM membranes for micropollutant removal.

Effect of Polycation. To obtain more knowledge about the packing density, amount of chains per volume, of the different PEM membranes, permeability and molecular weight cutoff (MWCO) experiments were performed with the results shown in Figure 3. Permeability gives information about how easily
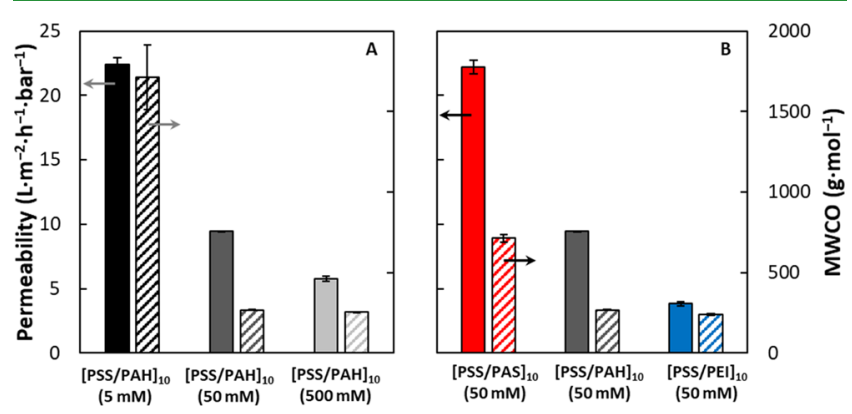

Figure 3. (A) Permeability (left) and MWCO (right) of [PSS/ $\mathrm{PAS}]_{10}$, $[\mathrm{PSS} / \mathrm{PAH}]_{10}$, and $[\mathrm{PSS} / \mathrm{PEI}]_{10} \mathrm{PEM}$ membranes prepared at a fixed salt concentration of $50 \mathrm{mM} \mathrm{NaCl}$. (B) Permeability (left) and MWCO (right) of $[\mathrm{PSS} / \mathrm{PAH}]_{10}$ prepared at salt concentrations of 5, 50 , and $500 \mathrm{mM} \mathrm{NaCl}$. MWCO is measured at a crossflow velocity of $1 \mathrm{~m} \cdot \mathrm{s}^{-1}$, a pressure of $2 \mathrm{bar}$, and a temperature of $20^{\circ} \mathrm{C}$. Error bars are standard errors from measurement of five separate membrane modules.

water passes through the PEM, e.g., high permeability means low resistance for water to permeate through the layer. Subsequently, when the PEM is denser, permeability will be lower due to densely packed PE chains; therefore, the effective pore size will be small due to a high interchain network density leading to a small mesh size. However, a simple increase in thickness also leads to lower permeability although the density of the PEM will stay the same. Here, MWCO experiments give additional knowledge about the density of the multilayer. In this experiment, neutral PEG molecules of various sizes are retained by the PEM membranes, which is again an indication of the packing density of the PE chains within the multilayer, one that does not depend on layer thickness. In Figure 3A, the permeability (left axis) and MWCO (right axis) of [PSS/ $\mathrm{PAH}]_{10}$ PEM membranes are plotted as a function of the salt concentration used during preparation. When a $[\mathrm{PSS} / \mathrm{PAH}]_{10}$ PEM is fabricated at $5 \mathrm{mM}$, the PEM membrane has a water permeability of $22 \mathrm{~L} \cdot \mathrm{m}^{-2} \cdot \mathrm{h}^{-1} \cdot \mathrm{bar}^{-1}$ and the permeability decreases to 9 and $6 \mathrm{~L} \cdot \mathrm{m}^{-2} \cdot \mathrm{h}^{-1} \cdot \mathrm{bar}^{-1}$ when the ionic strength used during preparation is increased to 50 and $500 \mathrm{mM}$, respectively. The permeability decreases at higher salt concentrations due to the higher adsorbed amount of the polyelectrolytes and thus thicker layers are formed, as shown by the reflectometry results in Figure 2A. These results are similar to studies performed on PSS/PDADMAC PEM membranes where the permeability is also highly dependent on the salt concentration used during preparation. ${ }^{15}$ In the same figure, the MWCO is plotted and it is observed that at 5 $\mathrm{mM}$ the $\mathrm{MWCO}$ is very high, which indicates that this layer has pinhole defects because the pores of the support are not fully covered. The MWCO for the PEMs prepared at 50 and $500 \mathrm{mM}$ is much lower and similar to each other. At these higher salt concentrations, the multilayers are thicker, and therefore, the pores are fully covered and a defect-free multilayer is formed with a low MWCO. ${ }^{15}$

In Figure 3B, the water permeability (left axis) and MWCO (right axis) are plotted for the $[\mathrm{PSS} / \mathrm{PAS}]_{10},[\mathrm{PSS} / \mathrm{PAH}]_{10}$, and $[\mathrm{PSS} / \mathrm{PEI}]_{10}$ PEM membranes that were prepared at the same salt concentration of $50 \mathrm{mM} \mathrm{NaCl}$. It is known that increasing the charge density (number of ion pairs per number of carbon atoms) of a PEM results in higher retentions toward ions. $^{46}$ In this study, PSS/PAH, PSS/PEI, and PSS/PAS have, respectively, an ion pair per number of carbon atoms of $1 / 11$, $1 / 10$, and $1 / 16$. Here, PSS/PAH and PSS/PEI are close together and have high charge densities, whereas PSS/PAS has a low number of ion pairs per number of carbon atoms and therefore a low charge density. When the various PEMs are tested, it is observed that by switching the chemistry using another polycation, large differences in permeability and MWCO are found. When comparing $[\mathrm{PSS} / \mathrm{PAH}]_{10}$ to $[\mathrm{PSS} /$ $\mathrm{PEI}]_{10}$, the permeability decreases from 9 to $4 \mathrm{~L} \cdot \mathrm{m}^{-2} \cdot \mathrm{h}^{-1} \cdot \mathrm{bar}^{-1}$ and the MWCO decreases from 267 to $239 \mathrm{~g} \cdot \mathrm{mol}^{-1}$. This is a $56 \%$ change in permeability, which is noticeably lower than any of the PSS/PAH PEM membranes used in this study. This is surprising as the PEI/PSS layer is expected to be thinner (Figure 2A) than the PAH/PSS layer. Together with the observed lower MWCO, this indicates that the PEM is significantly denser when the polycation is changed from $\mathrm{PAH}$ to PEI. However, the PSS/PEI multilayer is much denser than expected since the polyelectrolyte charge densities of both PSS/PAH and PSS/PEI are similar. The increased density of the PSS/PEI multilayer can be explained by the much lower excess of polycation present, which helps create a more stoichiometric multilayer. A more stoichiometric multilayer will result in less swelling of the layer (as the charge is lower) and better ion pairing ${ }^{47}$ and therefore will result in a higher packing density of PE chains. On the contrary, when PAS is used as a polycation, the polyelectrolyte charge density is lower than for PSS/PAH and PSS/PEI and this results in a high permeability for the $[\mathrm{PSS} / \mathrm{PAS}]_{10}$ membrane of $22 \mathrm{~L} \cdot \mathrm{m}^{-2} \cdot \mathrm{h}^{-1}$. $\mathrm{bar}^{-1}$, an increase of $144 \%$ with respect to the PSS/PAH multilayer membrane built at the same salt concentration. The MWCO of the PEM membranes matches this change in water permeability. Here, the MWCO increases from $267 \mathrm{~g} \cdot \mathrm{mol}^{-1}$ for the PSS/PAH membrane to $713 \mathrm{~g} \cdot \mathrm{mol}^{-1}$ for the PSS/PAS membrane, indicating a more open PEM when PAS is used as the polycation. Importantly though, the MWCO measured for the PSS/PAS membranes is still well within the nanofiltration regime and the higher $\mathrm{MWCO}$ is in line with the higher water permeability observed. Moreover, even though the PSS/PAS multilayer constructed with $50 \mathrm{mM}$ salt has a similar $\mathrm{PE}$ adsorption behavior as a $5 \mathrm{mM} \mathrm{PSS} / \mathrm{PAH}$ multilayer (see Figure 2), for the PAS case, a defect-free multilayer can be prepared unlike for the $5 \mathrm{mM}$ PSS/PAH case.

When looking at the retention values toward $\mathrm{NaCl}$ that are presented in Figure $4 \mathrm{~A}$, for the $[\mathrm{PSS} / \mathrm{PAH}]_{10}$ PEM membranes, the retention increases with increasing salt concentration used during buildup. This is a result of increasing positive charge within the multilayer when the salt concentration increases. However, like shown in Figure 2C, the amount of excess $\mathrm{PAH}$ in a PSS/PAH multilayer with regard to PSS is fixed and independent of the salt concentration. For this 


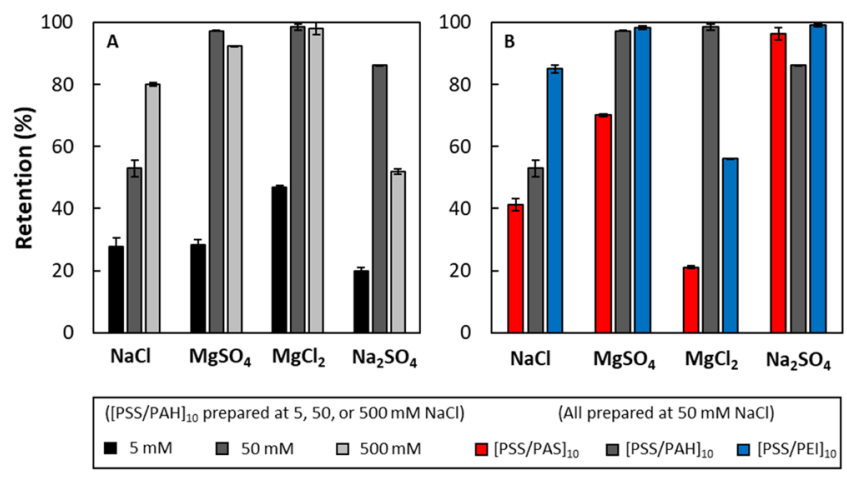

Figure 4. (A) Retention of various ions $\left(\mathrm{NaCl}, \mathrm{MgSO}_{4}, \mathrm{Na}_{2} \mathrm{SO}_{4}\right.$, and $\mathrm{MgCl}_{2}$ ) with $[\mathrm{PSS} / \mathrm{PAH}]_{10} \mathrm{PEM}$ membranes prepared at 5, 50, and $500 \mathrm{mM} \mathrm{NaCl}$. Retention is measured at a crossflow velocity of $1 \mathrm{~m}$. $\mathrm{s}^{-1}$, a pressure of $6.2 \mathrm{bar}$, and a temperature of $20^{\circ} \mathrm{C}$. (B) Retention of the same ions with $[\mathrm{PSS} / \mathrm{PAS}]_{10},[\mathrm{PSS} / \mathrm{PAH}]_{10}$, and $[\mathrm{PSS} / \mathrm{PEI}]_{10}$ PEM membranes prepared at a fixed salt concentration of $50 \mathrm{mM}$ $\mathrm{NaCl}$. Error bars are standard errors from measurements on five separate membrane modules.

reason, the increasing positive charge, and therefore $\mathrm{NaCl}$ retention, is most likely due to an increasing amount of extrinsic charge within the multilayer due to the high salt concentration used during buildup. The $[\mathrm{PSS} / \mathrm{PEI}]_{10} \mathrm{PEM}$ membrane has the lowest water permeability and MWCO of all PEMs (Figure 3A), and it is also the membrane with the highest retention toward $\mathrm{NaCl}$, when compared to the other PEMs build at the same salt concentration (Figure 4B). This is again in line with the dense packing of the PE chains, which translates into high dielectric exclusion and therefore high ion retentions. Conversely, the $[\mathrm{PSS} / \mathrm{PAS}]_{10}$ PEM membrane with the most open structure has naturally the highest water permeability and also the lowest $\mathrm{NaCl}$ retention due to a low packing and charge density of PE chains. These results show that both the packing density of polyelectrolyte chains (low or high permeability), the charge density, and excess amount of monomers of the multilayer greatly influence the retention toward salt ions.

Measuring $\mathrm{MgSO}_{4}$ retention gives useful information since two divalent ions have to be retained by the membrane instead of monovalent $\mathrm{Na}^{+}$and $\mathrm{Cl}^{-}$ions. In most cases, retentions for $\mathrm{MgSO}_{4}$ are higher than for $\mathrm{NaCl}$. In Figure 4A, it is observed that $\mathrm{MgSO}_{4}$ retentions are high for each PSS/PAH PEM membrane, except for the defect containing the $[\mathrm{PSS} / \mathrm{PAH}]_{10}$ multilayer constructed at $5 \mathrm{mM} \mathrm{NaCl}$. Moreover, a small decrease in $\mathrm{MgSO}_{4}$ retention is observed when the multilayer is prepared at $500 \mathrm{mM}$ instead of $50 \mathrm{mM}$. As explained in the previous paragraph, this could be due to the increased amount of extrinsic charge within the bulk of the multilayer due to the higher salt concentration used during buildup. For this reason, a higher positive charge within the bulk of the multilayer can create a higher sulfate affinity, meaning that less $\mathrm{MgSO}_{4}$ will be retained. In Figure 4B, the $\mathrm{MgSO}_{4}$ retentions of PSS/PAS and PSS/PEI membranes are compared to PSS/PAH prepared at the same salt concentration of $50 \mathrm{mM}$. Here, it is shown that PSS/PAS membranes have a good $\mathrm{MgSO}_{4}$ retention and the PSS/PEI membranes have a very high retention of $\mathrm{MgSO}_{4}$. The high retention of PSS/PEI PEM membranes is most likely due to a combined effect of surface/bulk charge, dielectric, and size exclusion because of the densely packed multilayer.

Focusing on the $\mathrm{MgCl}_{2}$ retentions presented in Figure 4A, it is clear that the retention of $\mathrm{MgCl}_{2}$ is high (>95\%) for the $[\mathrm{PSS} / \mathrm{PAH}]_{10}$ multilayers constructed at 50 and $500 \mathrm{mM}$, in line with the reflectometry and $\zeta$-potential results that reveal a positive bulk and surface charge. The low $\mathrm{MgCl}_{2}$ retention for the PSS/PAH membrane constructed at $5 \mathrm{mM}$ is due to pinhole defects. However, in comparison, the $[\mathrm{PSS} / \mathrm{PEI}]_{10}$ multilayer membranes shown in Figure $4 \mathrm{~B}$ have a lower retention for $\mathrm{MgCl}_{2}$ than the PSS/PAH membranes (50 and $500 \mathrm{mM}$ ), indicating a less positively charged surface and bulk. A similar behavior is observed for the more open $[\mathrm{PSS} / \mathrm{PAS}]_{10}$ membranes, where the $\mathrm{MgCl}_{2}$ retention is even lower. For both the PSS/PEI and PSS/PAS membranes, this is completely in line with the $\zeta$-potential results, which show a negative membrane surface potential. For $\mathrm{Na}_{2} \mathrm{SO}_{4}$ retention, in general for the PSS/PAH membranes, a lower retention is measured than for $\mathrm{MgCl}_{2}$. For the $[\mathrm{PSS} / \mathrm{PAH}]_{10}$ multilayer membranes, the retention toward $\mathrm{Na}_{2} \mathrm{SO}_{4}$ is lower for the PEM membrane constructed at $500 \mathrm{mM}$ salt compared to the PEM membrane constructed at $50 \mathrm{mM}$. This behavior is most probably due to the greater amount of extrinsic charge present within the multilayer and therefore an effective higher positive charge. For both the PSS/PEI and PSS/PAS membranes, the very high retentions toward $\mathrm{Na}_{2} \mathrm{SO}_{4}$ are in line with the negative surface charge of the membranes (see $\zeta$-potential results).

All information from the previous sections is qualitatively summarized in Table 3, where it is shown by water permeability, MWCO, and retention of various ions that the PSS/PAH PEM membranes are overall positively charged in the bulk and surface, are dense, and have a high dielectric exclusion toward ions since overall high retentions toward all ions are obtained. The PSS/PAS membranes, on the other hand, are negatively charged, have an open structure, and ion retentions are low and Donnan-exclusion-based, since sulfate retentions are high and magnesium retentions very low. ${ }^{21}$ The PSS/PEI membranes are negatively charged, the densest of the PEM membranes studied in this work with the lowest permeability and MWCO and high ion retentions, especially for the divalent negative ions. The much lower retention for $\mathrm{MgCl}_{2}$ indicates Donnan exclusion as a separation mechanism, while dielectric exclusion is likely to contribute. Overall, the

Table 3. Summary of the PEM Properties Based on Their Nanofiltration Performances for $[\mathrm{PSS} / \mathrm{PAS}]_{10},[\mathrm{PSS} / \mathrm{PAH}]_{10}$, and $[\mathrm{PSS} / \mathrm{PEI}]_{10}$ PEM Membranes Prepared at $50 \mathrm{mM}$ of $\mathrm{NaCl}$

\section{PSS/PAS}

low charge density $1 / 16$ ion pair per carbon atoms low packing density of PE chains

negative surface charge

low excess of polycation/low swelling potential

high permeability

low overall ion retention Donnan exclusion
PSS/PAH

PSS/PEI

high charge density $1 / 11$ ion pair per carbon atoms high charge density $1 / 10$ ion pair per carbon atoms high packing density of $\mathrm{PE}$ chains positive surface charge

high excess of polycation/high swelling potential medium permeability

high overall ion retention dielectric exclusion high packing density of $\mathrm{PE}$ chains

negative surface charge

low excess of polycation/low swelling potential

low permeability

high overall ion retention Donnan + dielectric exclusion 
trend is seen that when the charge density of a PEM increases, the packing density of the PEM becomes higher.

Effect of Cross-Linking. In Figure 5, the MWCO is plotted as a function of the membrane permeability; here, it can be

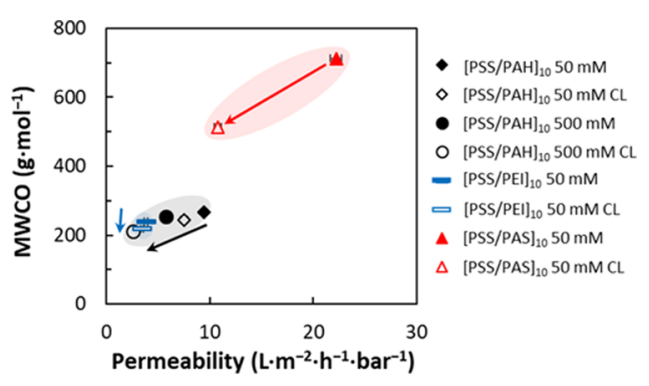

Figure 5. MWCO as a function of the permeability for $[\mathrm{PSS} / \mathrm{PAH}]_{10}$, $[\mathrm{PSS} / \mathrm{PAS}]_{10}$, and $[\mathrm{PSS} / \mathrm{PEI}]_{10}$ PEM membranes. Solid symbols are non-cross-linked PEMs, and open symbols are cross-linked PEMs. Note: CL stands for cross-linked. Black symbols are $[\mathrm{PSS} / \mathrm{PAH}]_{10}$ PEMs prepared at $5 \mathrm{mM}$ (squares), $50 \mathrm{mM}$ (diamonds), and $500 \mathrm{mM}$ $\mathrm{NaCl}$ (circles). Red triangle symbols are $[\mathrm{PSS} / \mathrm{PAS}]_{10} \mathrm{PEMs}$, and blue rectangles are $[\mathrm{PSS} / \mathrm{PEI}]_{10}$ PEMs. MWCO is measured at a crossflow velocity of $1 \mathrm{~m} \cdot \mathrm{s}^{-1}$, a pressure of $2.0 \mathrm{bar}$, and a temperature of $20^{\circ} \mathrm{C}$. Error bars are standard errors from measurements on five separate membrane modules.

clearly seen that when the permeability goes down, the MWCO decreases following the permeability-selectivity tradeoff. ${ }^{48}$ During cross-linking, the chemistry for all PEMs is the same: the primary amines react with GA, forming an imine bond. ${ }^{6}$ Subsequently, for all of the PEM membranes studied, the effect of cross-linking is similar, i.e., after cross-linking, all of the membranes have a lower water permeability and lower MWCO.

In Figure 6, all of the ion retentions for the non-cross-linked and cross-linked PEM membranes are plotted as a function of their water permeabilities. For all of the $[\mathrm{PSS} / \mathrm{PAH}]_{10}$ membranes, (black symbols) cross-linking results in lower retentions toward $\mathrm{NaCl}$. This is surprising as the MWCO results shown in Figure 5 suggest that the PEMs become denser after cross-linking. A possible explanation for the decrease in $\mathrm{NaCl}$ retention is that the charge balance within the bulk of the multilayer changes due to the reaction of glutaraldehyde with $\mathrm{PAH} .{ }^{6,49}$ The effect of cross-linking on $\mathrm{NaCl}$ retention is the most significant for $\mathrm{PSS} / \mathrm{PAH}$ multilayers constructed at $500 \mathrm{mM}$. When looking at the [PSS/ $\mathrm{PEI}]_{10}$ membranes (blue symbols), an increase in $\mathrm{NaCl}$ retention from 85 to $89 \%$ is observed after cross-linking. Similarly, the $[\mathrm{PSS} / \mathrm{PAS}]_{10}$ membranes (red symbols) also show an increasing retention toward $\mathrm{NaCl}$ after cross-linking. Here, the increases in $\mathrm{NaCl}$ retentions are in line with the MWCO results of Figure 5, and these data both support the conclusion that the PEMs become denser (increased chain packing density).

In Figure $6 \mathrm{~B}$, it is shown that after cross-linking, the retention toward $\mathrm{MgSO}_{4}$ is not affected for any of the PEM membranes (only the water permeability is influenced). Here, either a densification and/or altering of the surface charge after cross-linking means that the $\mathrm{MgSO}_{4}$ retention remains high. For $\mathrm{MgCl}_{2}$ and $\mathrm{Na}_{2} \mathrm{SO}_{4}$, shown in Figure 6C,D respectively, for all PSS/PAH membranes, cross-linking leads to lower retentions toward $\mathrm{MgCl}_{2}$ and increased retentions toward $\mathrm{Na}_{2} \mathrm{SO}_{4}$. This indicates that the overall charge of the multilayer
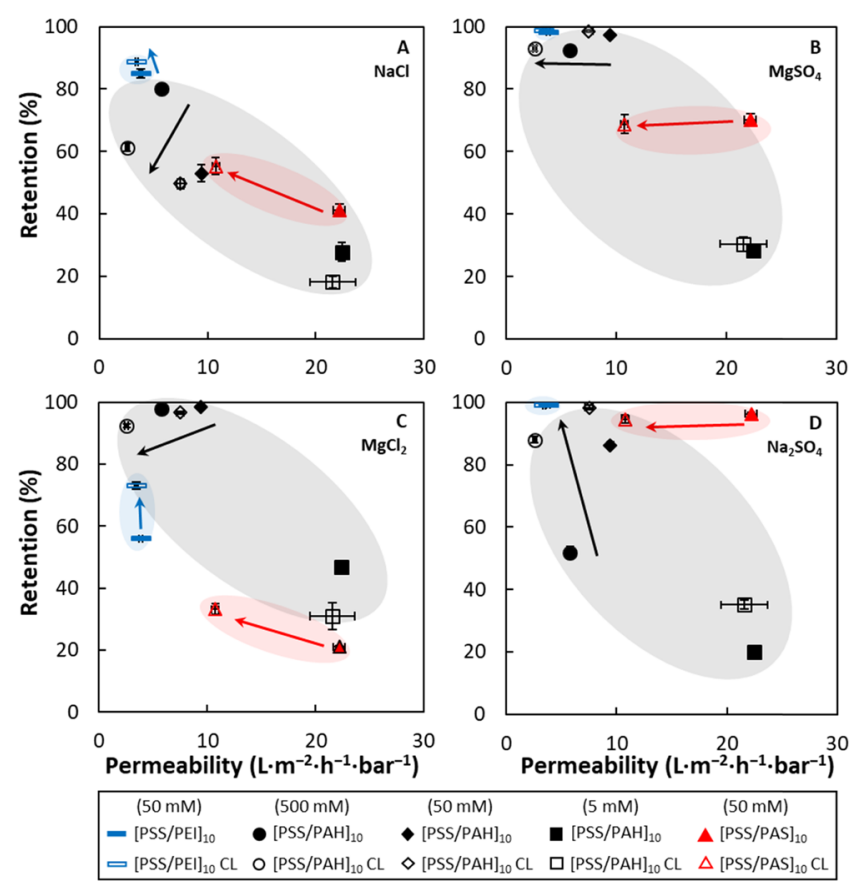

Figure 6. Retention of $5 \mathrm{mM} \mathrm{NaCl}(\mathrm{A}), \mathrm{MgSO}_{4}$ (B), $\mathrm{MgCl}_{2}$ (C), and $\mathrm{Na}_{2} \mathrm{SO}_{4}$ (D) as a function of the permeability. Solid symbols are noncross-linked PEM membranes, and open symbols are cross-linked PEM membranes. Note: CL stands for cross-linked. Black symbols are PSS/PAH membranes at which squares are the membranes built up at $5 \mathrm{mM}$, diamonds at $50 \mathrm{mM}$, and circles at $500 \mathrm{mM} \mathrm{NaCl}$. Blue rectangle symbols are PSS/PEI membranes, and red triangle symbols are PSS/PAS membranes, both built up at $50 \mathrm{mM} \mathrm{NaCl}$. Retention is measured at a crossflow velocity of $1 \mathrm{~m} \cdot \mathrm{s}^{-1}$, a pressure of $6.2 \mathrm{bar}$, and a temperature of $20{ }^{\circ} \mathrm{C}$. Error bars are standard errors from measurements on five separate membrane modules. Colored regions are a guide for the eye.

becomes less positive. ${ }^{49}$ This is logical because GA reacts with the primary amine groups of $\mathrm{PAH}$ forming an imine; therefore, the total amount of charge is effectively decreased after reaction with GA. For both the PSS/PEI and PSS/PAS membranes, the opposite is observed where upon cross-linking the $\mathrm{MgCl}_{2}$ retention goes up while maintaining the same $\mathrm{Na}_{2} \mathrm{SO}_{4}$ retention. For PEI-based membranes, only the primary amines react; therefore, only one-third of the amines present can react with GA. It could be due to an increase in packing density that the charge density increases since the secondary and tertiary amines are pulled more closely together. This is in line with a previous study on PEI-based membranes where after cross-linking with terephthalaldehyde, the charge of the membranes becomes less negative. ${ }^{16}$ For PSS/PAS, an increase in density can lead to a higher charge density within the multilayer, ensuring an overall higher ion retention.

Overall, the effect of cross-linking on membrane structure and performance is the same for all PEMs (denser structure, lower overall charge, and lower MWCO), but the degree depends on the multilayer composition, i.e., the polycation used. Here, PSS/PAH undergoes the largest changes upon cross-linking, clearly showing a change in charge balance within the multilayer where the PEM becomes less positively charged within the bulk. However, PSS/PEI and PSS/PAS show an overall increase in ion retention upon cross-linking due to an increasing packing density of the PE chains. 

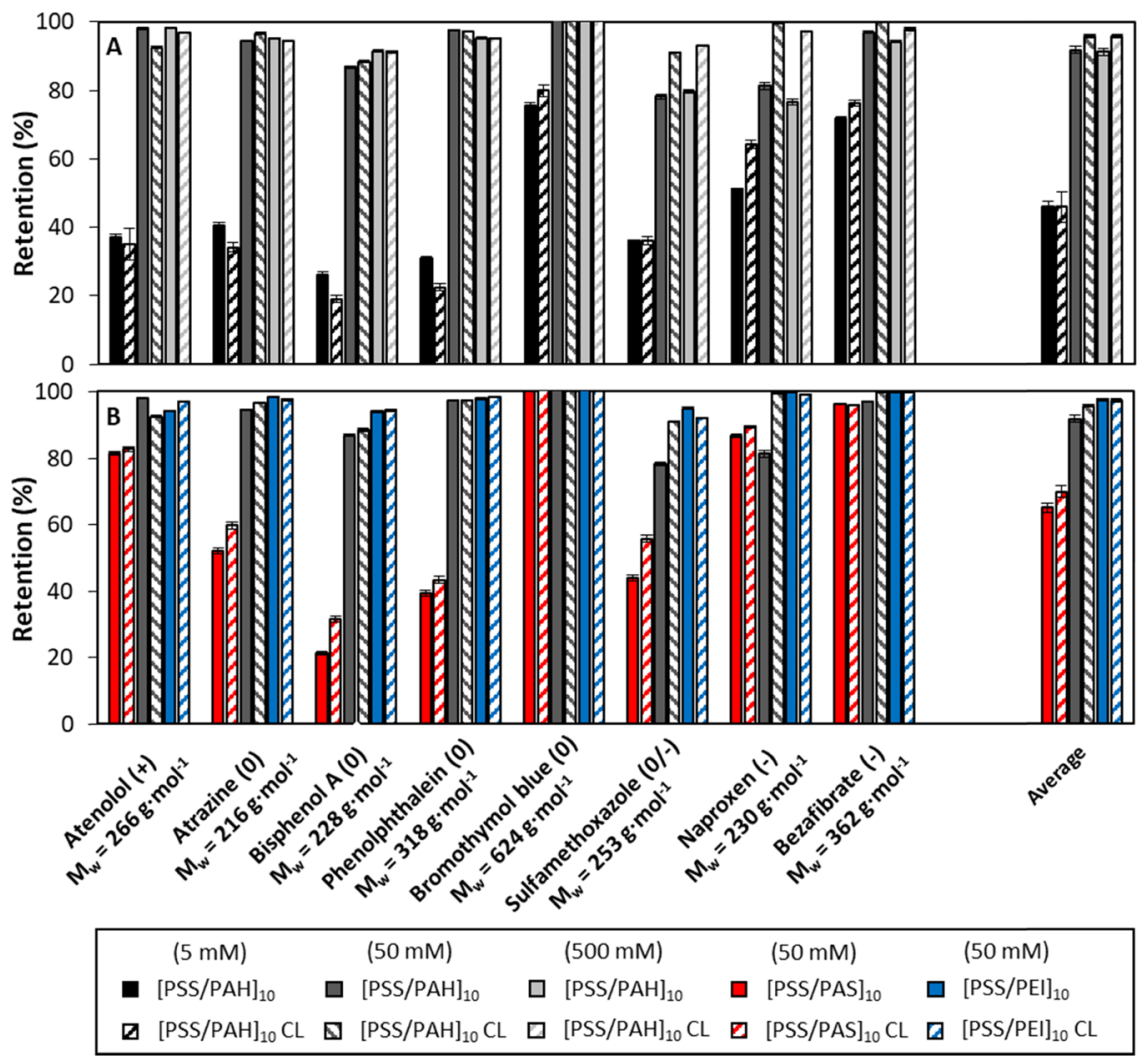

Figure 7. Micropollutant retention as a function of various micropollutants sorted from left to right based on their charge (left positive, middle neutral, and right negative). (A) Retention of the $[\mathrm{PSS} / \mathrm{PAH}]_{10}$ multilayer constructed at 5,50, and $500 \mathrm{mM} \mathrm{NaCl}$ (black, gray, and light-gray, respectively). (B) Retention of $[\mathrm{PSS} / \mathrm{PEI}]_{10}$ and $[\mathrm{PSS} / \mathrm{PAS}]_{10}$ multilayers in red and blue, respectively. In both graphs, solid bars represent noncross-linked multilayer membranes and patterned bars represent cross-linked multilayer membranes. Note: CL stands for cross-linked. Error bars are standard errors from measurements on five separate membrane modules.

PEM Membranes for Micropollutant Separation. To evaluate the performance of all of the PEM membranes used in this study, difficult-to-remove molecules that are harmful for humans and the environment (micropollutants) are treated by the fabricated PEM membranes. In Figure 7A,B, the micropollutant retentions are given for all PEM membranes used in this study. The mixture used contains various micropollutants of different molecular weights (200-650 Da), and they are positively charged, negatively charged, or have no overall charge at the chosen $\mathrm{pH}$ of 5.8. Phenolphthalein and bromothymol blue, both $\mathrm{pH}$ indicators, are added to ensure an even molecular weight distribution.

Interestingly, the retention of micropollutants gives valuable information about the exclusion mechanism of the PEMs and therefore indirectly provides insights into the structure of the multilayer. In this study, the micropollutant retentions will be coupled to all previous results to develop a deeper understanding of the multilayer structure. First, Figure 7A shows the micropollutant retention for $[\mathrm{PSS} / \mathrm{PAH}]_{10}$ membranes constructed at 5,50 , and $500 \mathrm{mM} \mathrm{NaCl}$ for the solid-black, gray, and light-gray bars, respectively. The micropollutant retentions for the cross-linked membranes are shown by patterned bars on the right side of the corresponding PEM membrane. For the non-cross-linked PSS/PAH membranes constructed at 5 $\mathrm{mM}$ salt, the overall retention is low and this is especially true for positively charged $(+)$ and neutral (0) micropollutants. For the PSS/PAH multilayers constructed at 50 and $500 \mathrm{mM}$ $\mathrm{NaCl}$, an overall high retention toward micropollutants is observed. Especially high retentions toward positively charged atenolol and neutral micropollutants are seen. The retentions drop for negatively charged micropollutants, except for bezafibrate because of its relatively high molecular weight. After cross-linking, the retentions toward neutral and negatively charged micropollutants increase for these PSS/ $\mathrm{PAH}$ membranes (50 and $500 \mathrm{mM}$ ), while the retention toward positively charged micropollutants goes down. These findings are in line with the earlier results that show that the membranes become less positively charged and denser after cross-linking (Figures 5 and 6).

For the PSS/PAS membranes (red bars in Figure 7B), the retentions toward both positively and negatively charged species, i.e., atenolol $(+)$, naproxen $(-)$, and bezafibrate $(-)$, are higher than one would expect from the measured MWCO of this membrane. However, the neutral micropollutants are retained less than the negative ones, which is more in line with the measured MWCO. Moreover, the complete removal of bromothymol blue indicates a defect-free separation layer. For the cross-linked PSS/PAS membrane, it is observed that the retention toward neutral micropollutants increases; however, no increasing retention is observed toward charged micropollutants. This result is in line with the MWCO results and the ion retention results because MWCO goes down while ion retentions change only slightly. The PSS/PEI membranes (blue bars in Figure 7B) have a high retention toward every micropollutant, and complete removal for naproxen $(-)$ and bezafibrate (-) is found, in line with the Donnan exclusion expected for this multilayer. Upon cross-linking, micro- 
pollutant retentions for the PSS/PEI membranes do not change significantly because the PEM is already very dense.

All three multilayer systems used in this study-PSS/PAH, PSS/PEI, and PSS/PAS - are based on the same polyanion, PSS, and the polycations contain cross-linkable primary amine groups. Comparison between the PEMs with different polycations is made at a building salt concentration of 50 $\mathrm{mM} \mathrm{NaCl}$. The PSS/PEI membrane is found to be the densest and the least permeable with the highest overall ion and micropollutant retentions. When the PSS/PEI multilayer is cross-linked, no change in water permeability and micropollutant retention is observed because the PEM already has a high density. The PSS/PAH membranes contain a high excess amount of $\mathrm{PAH}$; therefore, when these multilayers are crosslinked, a larger change in bulk charge is observed together with a densification of the multilayer. For the PSS/PAS membranes, a high densification of the multilayer is seen together with slightly increasing micropollutant retentions. In summary, cross-linking can be beneficial for PEM membranes to increase their performance; however, the effect of cross-linking depends strongly on the type of multilayer used.

\section{CONCLUSIONS}

In this study, the influence of polycation type (PAH, PEI, and PAS) and cross-linking on the structure and performance of PEM-coated nanofiltration membranes was investigated. PE adsorption measurements show that a $30-40 \%$ excess of PAH is present within the multilayers regardless of the building salt concentration $(5,50$, and $500 \mathrm{mM} \mathrm{NaCl})$, and this gives the membranes a positive surface charge. For the PSS/PEI and PSS/PAS membranes, the excess amount of polycation was lower (5-11 and 10-16\%, respectively). Furthermore, in contrast to the PSS/PAH multilayers, these PEM membranes had a negative surface charge even though they were polycation-terminated. At higher building salt concentrations, thicker PSS/PAH multilayers were formed, and this resulted in lower water permeabilities. When the PEMs were prepared at the same salt concentration $(50 \mathrm{mM} \mathrm{NaCl})$, the PSS/PEI membranes had a $56 \%$ lower permeability than the PSS/PAH membranes, whereas the PSS/PAS has a permeability $144 \%$ higher than the PSS/PAH membranes. In addition, MWCO experiments show that the PSS/PAH $\left(267 \mathrm{~g} \cdot \mathrm{mol}^{-1}\right)$ and the PSS/PEI $\left(239 \mathrm{~g} \cdot \mathrm{mol}^{-1}\right)$ multilayers are dense in structure, whereas the PSS/PAS multilayers were more open with a higher MWCO $\left(712 \mathrm{~g} \cdot \mathrm{mol}^{-1}\right)$ in line with the higher water permeability. The retention of various monovalent and divalent ions $\left(\mathrm{NaCl}, \mathrm{MgSO}_{4}, \mathrm{MgCl}_{2}\right.$, and $\mathrm{Na}_{2} \mathrm{SO}_{4}$ ) shows that the PSS/ PEI and PSS/PAH membranes were dense and had a high retention toward ions. However, the PSS/PAS membranes were more open than the PEI and PAH membranes and showed clear Donnan-exclusion-based retentions (high $\mathrm{Na}_{2} \mathrm{SO}_{4}$ and low $\mathrm{MgCl}_{2}$ retentions). Upon cross-linking, the packing density of the PEMs increased and this effect was the strongest when the PEMs were more open. Micropollutant retentions were the highest for the PSS/PEI membranes, which were the densest of the multilayers. Cross-linking resulted in higher overall micropollutant retentions for all PEMs except for the PSS/PEI membranes because they were already very dense. In conclusion, this work shows the versatility of PEM membranes since with a simple change in multilayer composition, hugely different membranes can be constructed. Moreover, cross-linking of PEM-coated membranes can be hugely beneficial to increase retention toward both micropollutants and ions.

\section{ASSOCIATED CONTENT}

\section{Supporting Information}

The Supporting Information is available free of charge at https://pubs.acs.org/doi/10.1021/acsapm.0c00992.

Refractive index increments as a function of polyelectrolyte concentration (PDF)

\section{AUTHOR INFORMATION}

\section{Corresponding Author}

W. M. de Vos - Membrane Science \& Technology, University of Twente, MESA+ Institute for Nanotechnology, 7500 AE

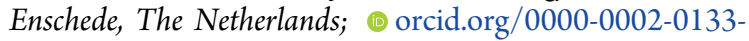
1931; Email: w.m.devos@utwente.nl

\section{Authors}

D. M. Reurink - Membrane Science \& Technology, University of Twente, MESA+ Institute for Nanotechnology, 7500 AE Enschede, The Netherlands

J. D. Willott - Membrane Science \& Technology, University of Twente, MESA+ Institute for Nanotechnology, 7500 AE

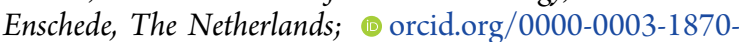
$755 \mathrm{X}$

H. D. W. Roesink - Membrane Science \& Technology, University of Twente, MESA+ Institute for Nanotechnology, 7500 AE Enschede, The Netherlands

Complete contact information is available at:

https://pubs.acs.org/10.1021/acsapm.0c00992

\section{Notes}

The authors declare no competing financial interest.

\section{ACKNOWLEDGMENTS}

This project was made possible through the financial support of Aquaporin A/S (Lyngby, Denmark) and the TKI HTSM through the University of Twente Impuls program. J.D.W. and W.M.d.V. acknowledge funding support from the "Vemieuwingsimpuls" program through project VIDI 723.015.003 (financed by the Netherlands Organisation for Scientific Research, NWO). The authors would like to thank Joris de Grooth for useful advice and discussions and Iske Achterhuis for all of the help with the membrane performance measurements.

\section{REFERENCES}

(1) Riegler, H.; Essler, F. Polyelectrolytes. 2. Intrinsic or extrinsic charge compensation? Quantitative charge analysis of PAH/PSS multilayers. Langmuir 2002, 18, 6694-6698.

(2) Bieker, P.; Schönhoff, M. Linear and Exponential Growth Regimes of Multilayers of Weak Polyelectrolytes in Dependence on pH. Macromolecules 2010, 43, 5052-5059.

(3) Shiratori, S. S.; Rubner, M. F. pH-dependent thickness behavior of sequentially adsorbed layers of weak polyelectrolytes. Macromolecules 2000, 33, 4213-4219.

(4) Lavalle, P.; Gergely, C.; Cuisinier, F. J. G.; Decher, G.; Schaaf, P.; Voegel, J. C.; Picart, C. Comparison of the Structure of Polyelectrolyte Multilayer Films Exhibiting a Linear and an Exponential Growth Regime: An in Situ Atomic Force Microscopy Study. Macromolecules 2002, 35, 4458-4465.

(5) Klitzing, R. v. Internal structure of polyelectrolyte multilayer assemblies. Phys. Chem. Chem. Phys. 2006, 8, 5012-5033. 
(6) An, Q.; Huang, T.; Shi, F. Covalent layer-by-layer films: chemistry, design, and multidisciplinary applications. Chem. Soc. Rev. 2018, 47, 5061-5098.

(7) Porcel, C.; Lavalle, P.; Decher, G.; Senger, B.; Voegel, J. C.; Schaaf, P. Influence of the polyelectrolyte molecular weight on exponentially growing multilayer films in the linear regime. Langmuir 2007, 23, 1898-1904.

(8) Richardson, J. J.; Bjornmalm, M.; Caruso, F. Multilayer assembly. Technology-driven layer-by-layer assembly of nanofilms. Science 2015, 348, No. aaa2491.

(9) Joseph, N.; Ahmadiannamini, P.; Hoogenboom, R.; Vankelecom, I. F. J. Layer-by-layer preparation of polyelectrolyte multilayer membranes for separation. Polym. Chem. 2014, 5, 1817-1831.

(10) Kidambi, S.; Dai, J. H.; Li, J.; Bruening, M. L. Selective hydrogenation by $\mathrm{Pd}$ nanoparticles embedded in polyelectrolyte multilayers. J. Am. Chem. Soc. 2004, 126, 2658-2659.

(11) Gorin, D. A.; Yashchenok, A. M.; Manturov, A. O.; Kolesnikova, T. A.; Mohwald, H. Effect of layer-by-layer electrostatic assemblies on the surface potential and current voltage characteristic of metal-insulator-semiconductor structures. Langmuir 2009, 25, 12529-12534.

(12) Saikaew, R.; Marsal, P.; Grenier, B.; Dubas, S. T. Temperature controlled loading and release of curcumin in polyelectrolyte multilayers thin films. Mater. Lett. 2018, 215, 38-41.

(13) Gu, B. B.; Aung, C. Y.; Chong, P. H. J.; Guan, Y. L.; Yong, K. T. Reversible and Fast Responsive Optical Fiber Relative Humidity Sensor Based on Polyelectrolyte Self-Assembly Multilayer Film. IEEE Sens. J. 2018, 18, 1081-1086.

(14) Decher, G. Fuzzy Nanoassemblies: Toward Layered Polymeric Multicomposites. Science 1997, 277, 1232-1237.

(15) de Grooth, J.; Oborný, R.; Potreck, J.; Nijmeijer, K.; de Vos, W. $\mathrm{M}$. The role of ionic strength and odd-even effects on the properties of polyelectrolyte multilayer nanofiltration membranes. J. Membr. Sci. 2015, 475, 311-319.

(16) Sinclair, T. R.; Patil, A.; Raza, B. G.; Reurink, D.; van den Hengel, S. K.; Rutjes, S. A.; de Roda Husman, A. M.; Roesink, H. D. W.; de Vos, W. M. Cationically modified membranes using covalent layer-by-layer assembly for antiviral applications in drinking water. $J$. Membr. Sci. 2019, 570-571, 494-503.

(17) Abdu, S.; Marti-Calatayud, M. C.; Wong, J. E.; GarciaGabaldon, M.; Wessling, M. Layer-by-layer modification of cation exchange membranes controls ion selectivity and water splitting. ACS Appl. Mater. Interfaces 2014, 6, 1843-1854.

(18) White, N.; Misovich, M.; Alemayehu, E.; Yaroshchuk, A.; Bruening, M. L. Highly selective separations of multivalent and monovalent cations in electrodialysis through Nafion membranes coated with polyelectrolyte multilayers. Polymer 2016, 103, 478-485. (19) Nunes, S. P.; Culfaz-Emecen, P. Z.; Ramon, G. Z.; Visser, T.; Koops, G. H.; Jin, W.; Ulbricht, M. Thinking the future of membranes: Perspectives for advanced and new membrane materials and manufacturing processes. J. Membr. Sci. 2020, 598, No. 117761.

(20) de Grooth, J.; Haakmeester, B.; Wever, C.; Potreck, J.; de Vos, W. M.; Nijmeijer, K. Long term physical and chemical stability of polyelectrolyte multilayer membranes. J. Membr. Sci. 2015, 489, 153159.

(21) Cheng, W.; Liu, C.; Tong, T.; Epsztein, R.; Sun, M.; Verduzco, R.; Ma, J.; Elimelech, M. Selective removal of divalent cations by polyelectrolyte multilayer nanofiltration membrane: Role of polyelectrolyte charge, ion size, and ionic strength. J. Membr. Sci. 2018, $559,98-106$.

(22) Hong, S. U.; Malaisamy, R.; Bruening, M. L. Optimization of flux and selectivity in $\mathrm{Cl}-/ \mathrm{SO} 42$ - separations with multilayer polyelectrolyte membranes. J. Membr. Sci. 2006, 283, 366-372.

(23) Malaisamy, R.; Talla-Nwafo, A.; Jones, K. L. Polyelectrolyte modification of nanofiltration membrane for selective removal of monovalent anions. Sep. Purif. Technol. 2011, 77, 367-374.

(24) Hong, S. U.; Malaisamy, R.; Bruening, M. L. Separation of fluoride from other monovalent anions using multilayer polyelectrolyte nanofiltration membranes. Langmuir 2007, 23, 1716-1722.
(25) Hong, S. U.; Lu, O. Y.; Bruening, M. L. Recovery of phosphate using multilayer polyelectrolyte nanofiltration membranes. J. Membr. Sci. 2009, 327, 2-5.

(26) Toutianoush, A.; Jin, W.; Deligöz, H.; Tieke, B. Polyelectrolyte multilayer membranes for desalination of aqueous salt solutions and seawater under reverse osmosis conditions. Appl. Surf. Sci. 2005, 246, 437-443.

(27) Jin, W.; Toutianoush, A.; Tieke, B. Use of Polyelectrolyte Layer-by-Layer Assemblies as Nanofiltration and Reverse Osmosis Membranes. Langmuir 2003, 19, 2550-2553.

(28) Ghostine, R. A.; Markarian, M. Z.; Schlenoff, J. B. Asymmetric growth in polyelectrolyte multilayers. J. Am. Chem. Soc. 2013, 135, $7636-7646$

(29) Reurink, D. M.; Haven, J. P.; Achterhuis, I.; Lindhoud, S.; Roesink, H. D. W.; de Vos, W. M. Annealing of Polyelectrolyte Multilayers for Control over Ion Permeation. Adv. Mater. Interfaces 2018, 5, No. 1800651.

(30) Elshof, M. G.; de Vos, W. M.; de Grooth, J.; Benes, N. E. On the long-term $\mathrm{pH}$ stability of polyelectrolyte multilayer nanofiltration membranes. J. Membr. Sci. 2020, 615, No. 118532.

(31) de Vos, W. M.; Mears, L. L. E.; Richardson, R. M.; Cosgrove, T.; Barker, R.; Prescott, S. W. Nonuniform Hydration and Odd-Even Effects in Polyelectrolyte Multilayers under a Confining Pressure. Macromolecules 2013, 46, 1027-1034.

(32) Duong, P. H. H.; Zuo, J.; Chung, T.-S. Highly crosslinked layerby-layer polyelectrolyte FO membranes: Understanding effects of salt concentration and deposition time on FO performance. J. Membr. Sci. 2013, 427, 411-421.

(33) Cui, Y.; Wang, H.; Wang, H.; Chung, T.-S. Micro-morphology and formation of layer-by-layer membranes and their performance in osmotically driven processes. Chem. Eng. Sci. 2013, 101, 13-26.

(34) Virga, E.; de Grooth, J.; Žvab, K.; de Vos, W. M. Stable Polyelectrolyte Multilayer-Based Hollow Fiber Nanofiltration Membranes for Produced Water Treatment. ACS Appl. Polym. Mater. 2019, $1,2230-2239$.

(35) Dijt, J. C.; Stuart, M. A. C.; Fleer, G. J. Reflectometry as a Tool for Adsorption Studies. Adv. Colloid Interface Sci. 1994, 50, 79-101.

(36) Dubas, S. T.; Schlenoff, J. B. Factors controlling the growth of polyelectrolyte multilayers. Macromolecules 1999, 32, 8153-8160.

(37) Abtahi, S. M.; Marbelia, L.; Gebreyohannes, A. Y.; Ahmadiannamini, P.; Joannis-Cassan, C.; Albasi, C.; de Vos, W. M.; Vankelecom, I. F. J. Micropollutant rejection of annealed polyelectrolyte multilayer based nanofiltration membranes for treatment of conventionally-treated municipal wastewater. Sep. Purif. Technol. 2019, 209, 470-481.

(38) Ormanci-Acar, T.; Mohammadifakhr, M.; Benes, N. E.; de Vos, W. M. Defect free hollow fiber reverse osmosis membranes by combining layer-by-layer and interfacial polymerization. J. Membr. Sci. 2020, 610, No. 118277.

(39) Liu, G.; Dotzauer, D. M.; Bruening, M. L. Ion-Exchange Membranes Prepared Using Layer-by-Layer Polyelectrolyte Deposition. J. Membr. Sci. 2010, 354, 198-205.

(40) Wang, Z.; Xia, J.; Luo, S.; Zhang, P.; Xiao, Z.; Liu, T.; Guan, J. Versatile surface micropatterning and functionalization enabled by microcontact printing of poly(4-aminostyrene). Langmuir 2014, 30, 13483-13490.

(41) Stanton, B. W.; Harris, J. J.; Miller, M. D.; Bruening, M. L. Ultrathin, multilayered polyelectrolyte films as nanofiltration membranes. Langmuir 2003, 19, 7038-7042.

(42) Yeo, S. J.; Kang, H.; Kim, Y. H.; Han, S.; Yoo, P. J. Layer-bylayer assembly of polyelectrolyte multilayers in three-dimensional inverse opal structured templates. ACS Appl. Mater. Interfaces 2012, 4, 2107-2115.

(43) Schlenoff, J. B.; Dubas, S. T. Mechanism of Polyelectrolyte Multilayer Growth: Charge Overcompensation and Distribution. Macromolecules 2001, 34, 592-598.

(44) Dubas, S. T.; Schlenoff, J. B. Swelling and smoothing of polyelectrolyte multilayers by salt. Langmuir 2001, 17, 7725-7727. 
(45) Schönhoff, M.; Ball, V.; Bausch, A. R.; Dejugnat, C.; Delorme, N.; Glinel, K.; Klitzing, R. V.; Steitz, R. Hydration and internal properties of polyelectrolyte multilayers. Colloids Surf., A 2007, 303, 14-29.

(46) Krasemann, L.; Tieke, B. Selective ion transport across selfassembled alternating multilayers of cationic and anionic polyelectrolytes. Langmuir 2000, 16, 287-290.

(47) Fu, J. C.; Fares, H. M.; Schlenoff, J. B. Ion-Pairing Strength in Polyelectrolyte Complexes. Macromolecules 2017, 50, 1066-1074.

(48) Werber, J. R.; Deshmukh, A.; Elimelech, M. The Critical Need for Increased Selectivity, Not Increased Water Permeability, for Desalination Membranes. Environ. Sci. Technol. Lett. 2016, 3, 112120.

(49) Percival, S. J.; Small, L. J.; Spoerke, E. D.; Rempe, S. B. Polyelectrolyte layer-by-layer deposition on nanoporous supports for ion selective membranes. RSC Adv. 2018, 8, 32992-32999. 